\title{
The English Syllable Structure within Optimality Theory
}

\section{Awan Kamal Muhammed}

College of Languages/ English Department/University of Salahadin.

Awankamal8@gmail.com

009647708268641

\section{Dr. Hamza Othman Maho Goran}

College of Languages/ English Department/University of Salahadin.

07504559505

zanadanazana@yahoo.com

ARTICLE INFO

Article History:

Received: 24/6/2019

Accepted: 28/7/2019

Published: Fall /2019

DOI:

10.25212/lfu.qzj.4.4.42

Keywords:

Optimality,

Constraints

Generator,

Eval

\begin{abstract}
This study deals with the optimality theory and the syllable structure within the hypothetical framework of the theory. The syllable has always played a central role in the phonological theory. But within the recent advent of Optimality theory, its role has become crucial in Linguistics. Optimality theory (OT), "is a linguistic model proposing that the observed forms of language arise from the optimal satisfaction of conflicting constraints". The study aims to investigate segments are to be syllabified in certain different ways and the fact that they should be syllabified. This paper has been divided into two sections: the first section focuses on the definition, concept, and components of the theory. The second section is concerned with the general theory of syllable within the framework of Optimality theory.
\end{abstract}

\section{Introduction}

This linguistic model Optimality Theory (hereafter, OT) is a hypothesis of dialect and language structure that turned out to be a significant prominent pattern in Linguistics after its presentation in 1993 by the phonologist Alan (Rutgers University, New Jersey) Prince and the Cognitive scientist Paul Smolensky (John Hopkins University, Baltimore) in the year 1993. It is a main presumption of the theory that 'there are no fixed bounds on language' (see Aitchaison, 2003, p.32). 
Another proof uncovering that this model is a present and productive one - i.e. alongside expanding and developing of Optimality Theory everywhere throughout the linguistic world - is its relevance to various subfields of linguistics, for example, phonology, syntax, and morphology. Although much interests of optimality theory is linked with its use in phonology as it was the first area that optimality theory firstly applied Optimality hypothesis has

to.

borrowed its fundamental aspects from Generative grammar structure, which shares its emphasis on the examination of universal principles, language acquisition, and linguistic typology.

The Theory hypothesizes that language structure is an input- output mechanism that combines an output structure to an input structure in such a way that each input has exactly one output (Kager, 2004, p.18). To achieve this purpose, the grammar contains a segment which equals the input with an interminable arrangement set of candidate output forms, and another segment that assesses the candidate output by a lot of ranked constraints, and chooses the ideal(optimal) output among these. These two segments are known as Generator and Evaluator, individually (cf. Vogel, 2004, p. 211). Generator or GEN is a function providing a variety of candidate linguistic analyses for a specific input GEN which creates a possible list of outputs (Kager (1999:20. ).

Likewise, Evaluator is a function providing the ideal(optimal) analysis of when connected to a lot of output candidates (cf. Vogel, the input form 2004, p. 211).

\section{CANDIDATE Comparison}

In optimality theory, the ranking of constraints can be appeared by a tableau, this can list two (or any number of) output candidates vertically in irregular order, and constraints horizontally, in a descending ranking from left to right. The cells contain violation marks '*' brought about by every candidate for constrain the adingthe column

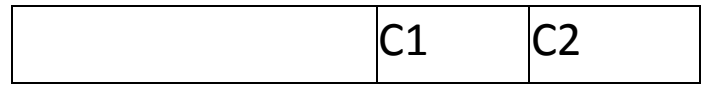




\begin{tabular}{|r|l|l|}
\hline candidate a $\mathrm{a}$. & & $*$ \\
\hline b. candidate $\mathrm{b}$ & $!^{*}$ & \\
\hline
\end{tabular}

\section{Table: 1 (Table used in optimality theory)}

This candidate ( $1 \mathrm{a})$, which has . The ideal candidate is set by the index no violation of the higher-ranked constraint $\mathrm{C} 1$, a constraint violated by its competitor (1 b) notice that the ideal (optimal) candidate (1a) is really not perfect itself: it has a violation of $\mathrm{C} 2$. However, this flaw is insignificant to the result. Even though the pattern of violation for $\mathrm{C} 2$ is the reverse of that for $\mathrm{C} 1$, this cannot happen to candidate $\mathrm{b}$. Its violation of $\mathrm{C} 1$ has been already fatal, shown by the following exclamation mark '!' moreover, the shading of cells whose violation content is never again applicable. To whole up, candidate (a) is ideal (optimal) as no applicant is accessible that fares better, fulfilling constraints in the meantime. A violation of $\mathrm{C} 2$ is fulfilled. (Kager,1999: p 13 underestimated, as long as C1 can be

Candidate comparison stays the same when there are different violation, and it is not important to count violation-marks, as better or worse execution is all that is taken into consideration. In addition, (Tesar and Smolensky, 2000, P. 119) present the strategy for 'mark cancellation'. only if a tableau compares precisely two candidates, violation marks that the two candidates offer can be ignored or dropped since that violation imprints nothing to that specific comparison. Mark cancellation is additionally helpful when candidates acquire different violation: when one candidate has three violation marks from some constraint while another candidate has five, mark cancellation diminishes this to zero and two, individually. Comparison, as opposed to counting, is what is important.

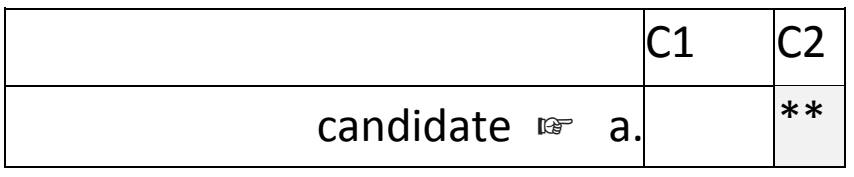




\section{b candidate

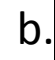

Table : 2 (more than one violation for one candidate)

\section{COMPONENTS OF OPTIMALITY THEORY}

\section{Generator 3.1}

In Optimality Theory, the GENERATOR or GEN is a function providing a variety of candidate linguistic analyses for specific input. So in keeping with this depiction, the ideas GEN and input appear to be firmly associated with one another. An input basically is selected from the LEXICON of any language (cf. Kager 1999, P. 19), and it is examined by the role of GEN which is creating a possible relative list of candidates to input. The input for phonology is a perfect abstract illustration of a lexical word"s appearance and it is examined by the function GEN which creates a possible list of The .Freedom of Analysis outputs and this property of Generator is called output candidates are then exactly what their names involve; they are candidates displayed to be attainable outputs (Kager, 1999, P.20. ). GEN consists of very broad principles of linguistic form, essentially limited "itself their most basic to those that define the representational primitives and Prince 1994: 4). So in another way, \& McCarthy) "modes of combinations GEN 'releases' an exceedingly general, theoretically endless list of candidates, which are pretty much demonstrated after the input form (cf. McCarthy and Prince 1993, P. 5; Nathan 2008, P 


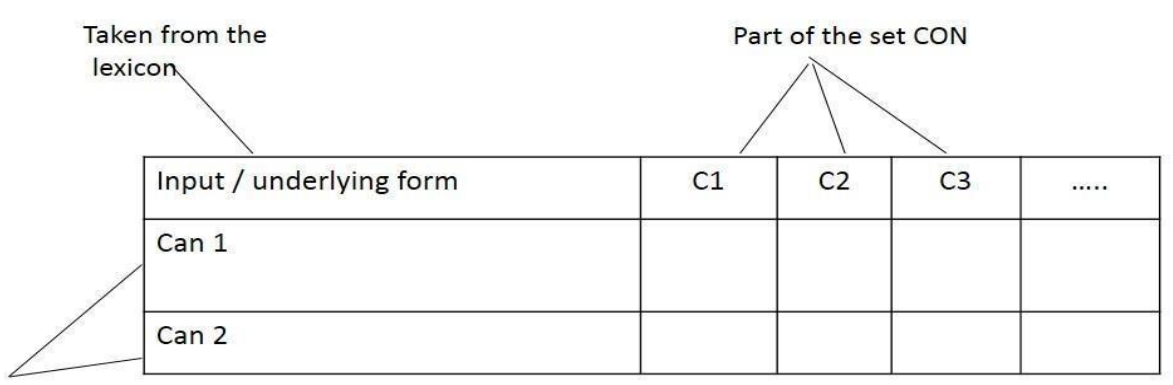

\section{Table:3}

here, the role of the essential concepts and underlying process in the could be clarified. above example

The input or underlying form is taken from the LEXICON and then, examined by the function GEN, which thus creates a list of candidates demonstrated to a limited degree after the respective input.

\section{Eval 3.2}

One of the characterizing features of OT is competition among candidates, and this challenge is settled in the Eval module. Eval considers candidates in pairwise correlations dependent on their relative performance with relation to the constraint hierarchy. EVAL chooses the out from a set of candidate starting from two to an infinite number (n). The figure in (1) bellow illustrates the process to reach an output from the Hannahs, \& input through the function of GEN and EVAL (Davenport 2005). Note that the following graphic representation is indicative only.

The actual output tableaux differ from this representation. 


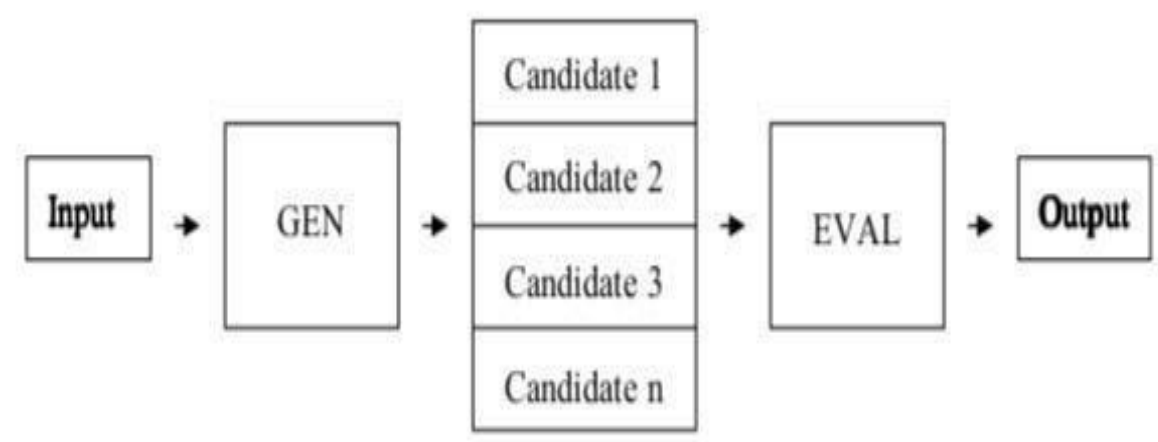

a structural requirement The introductory definition for constraints is A form can that may be either satisfied or violated by an output form. satisfy a constraint in case it totally fulfills the structural requirement, otherwise if the constraint does not fulfill the requirement it will showcase that it violates it (Kager 1999, p.2).

OT embraces two kinds of constraints, markedness and faithfulness constraints. Every individual evaluates one specific aspect of output markedness or faithfulness. . Markedness constraints enforce wellformedness of the output candidate, preventing structures that are difficult to produce or comprehend, such as consonant clusters or phrases without overt heads (Arbib 2002; Kager 1999,2). Markedness plays an important role which, in a soft sense, represents universality. The idea shows that kind of linguistics structures embrace two values which are " marked" and "unmarked". On the one hand, in cross-linguistics unmarked values are favored and fundamental in sentence structure while on the other hand marked values are kept off cross-linguistically and just used by grammars to make opposition (Kager, 2004, 2,9).

constraints is in contrast with markedness in which it takes into Faithfulness while markedness does not take, "input and output" consideration the levels that into consideration any component in the input. Thus it can be noticed the significant thing here is, however, that both constraints refer to the output it could be noticed that OT has no constraints that solely denotes to the input. From a practical point of view, faithfulness preserves the lexical power of markedness constraints, "eroding" item of any language from the In total, the general capacity or function thus it serves two major functions. 
of faithfulness is to implement the phonological form of lexical structures in the output, as a kind of inertness restricting the space or distance between their essential shapes (kager, 2004, output and

One should also need to consider the following constraint set, in order of domination (M: Markedness, F: descending Faithfulness):

1. M: *SS: Sibilant-Sibilant : adjacent sibilants will not be allowed and in the output it will get one violation.

2. M: Agree(Voi): Agree in specification of [voi]: One violation for every pair of adjacent obstruents in the output which disagree in voicing.

3. F: Ident(Voi): Maintains up an identity in the voicing of a sound's input and output states.

4. F: Max: The segment that is in the input but does not appear in the output will result in one violation thus this constraints prevents deletion.

5. F: Dep: if an output segment does not have input correspondent, it will result in one violation and this prevents epenthesis.

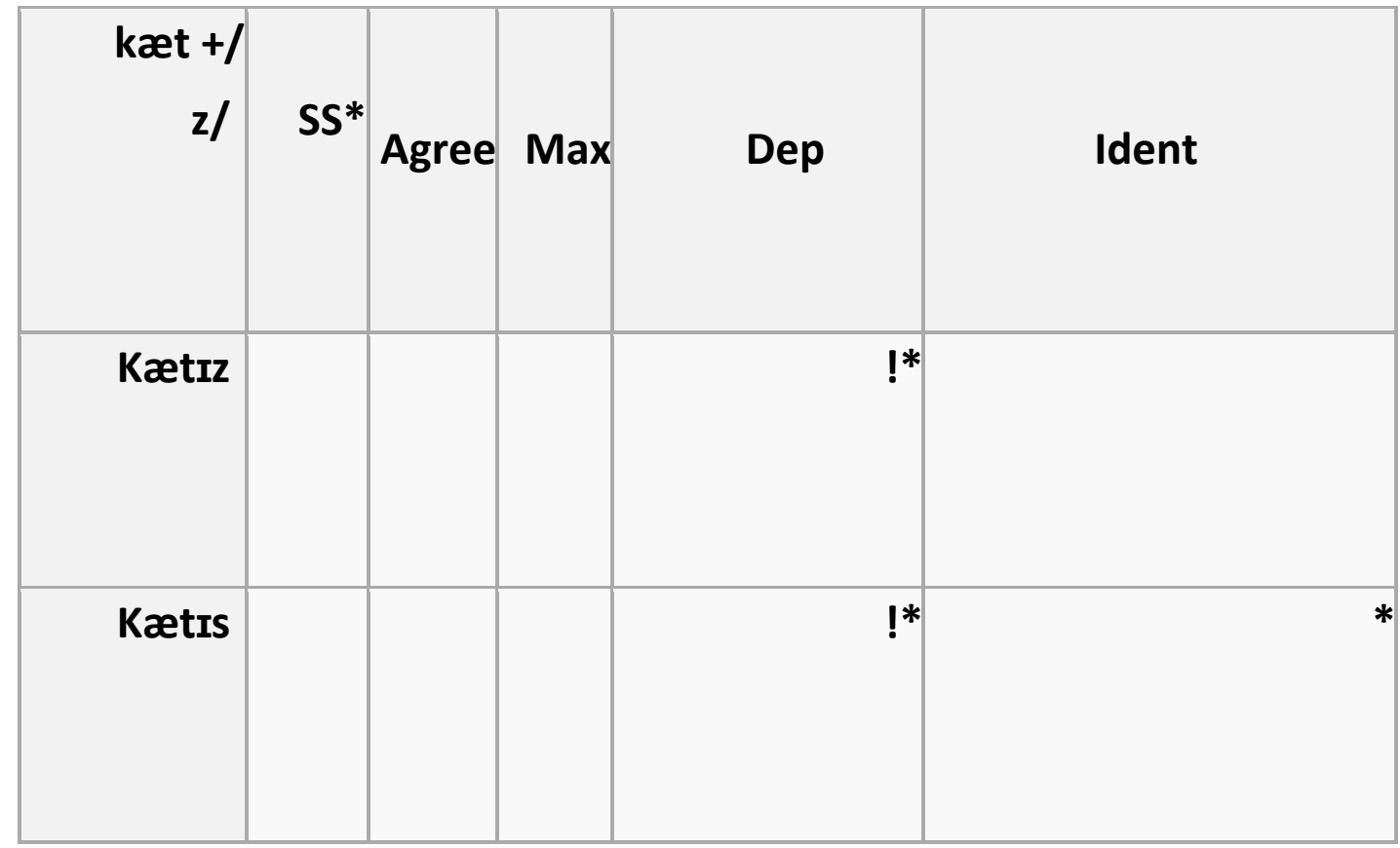




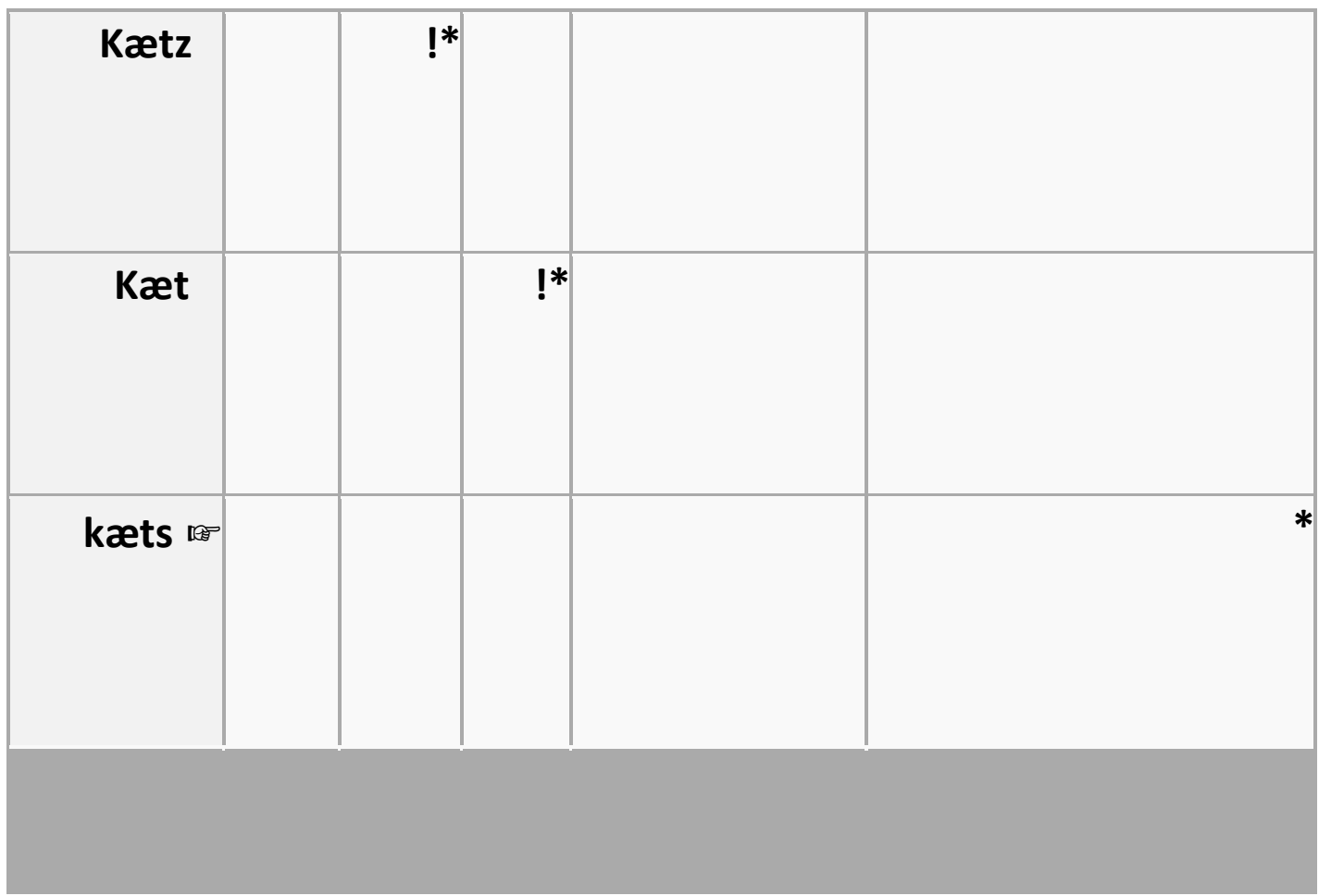

Table: 5

In this example several new constraints operate in order to select the correct optimal candidate. It does not matter how the constraints are This is called .'Iz' allomorph will always lose to 'Is' re-ordered, the Smolensky, 2002, p. \& Prince) 'harmonic bounding'

\section{THE SYLLABLE}

The fundamental attention to the syllable as a linguistic unit can be shown in the capacity of local speakers to calculate the number of syllables in their language. Researches on the position of the syllable in phonological hypothesis (e.g., Blevins, 1995; Khan, 1976; and numerous others) have taken local instincts about the presence of the syllable as a conceivable piece of proof to support the status of the syllable as a phonological unit, particularly in a hypothesis that attempts to represent the phonological knowledge of local speakers. 
In (Prince and Smolensky's 1993/2004) typology of syllable structure, the perception made in the phonological hypothesis that all languages permit $\mathrm{CV}$ syllables, yet they may contrast in regardless of whether the onset is weather the coda is permitted, has been caught in the requisite and accompanying typology.

\subsection{The General Theory of the Syllable}

Syllables differ regarding the number of moras they have. Moras customarily can be characterized as a unit of quantity for syllables. Most Linguists perceive monomoraic and bimoraic syllables; while others also perceive zero-moraic and trimoraic syllables. The investigation aims to represent (I) the way that strings segments can be syllabified and in specific ways and the way they should be syllabified.

To get to the way that they can be syllabified by any means, we must agree that GEN can comprise syllables. To drive the syllabic structure to be inserted, we a constraint requiring it. The applicable constraint has been should include Hammond, )

PARSE called 2003:46).

PARSE

Segments must be syllabified

The least difficult explanation of what can go where in a syllable requires differentiation between syllable margins and syllable peaks. All syllables must have one and just a single syllable peak. All the material that is around These suppositions are a the peak is comprised of the syllable margins. portion of GEN. The essential story for English could be said that vowels consonants must be syllable have to be syllable peaks and margins.

Assumingly there is a constraint schema that allocates violation when some segment is a syllable peak Call this*PEAK/X

\section{$\operatorname{PEAK} / \mathrm{X}^{*}$}

$\mathrm{X}$ must not be a syllable peak 
As an introductory statement, this schema is instantiated in English with a constraint:

Also, we will assume that there are similar schemata for onset and PEAK/C." coda:

ONSET/X and ${ }^{*} \operatorname{CODA} / \mathrm{X}^{*}$

CODA $/ X^{*}$

$X$ must not be an onset

CODA $/ X^{*}$

\section{$X$ must not be coda}

Again, as a preliminary statement, these schemata are instantiated in English as:

$$
\text { ONSET/V and*CoDA/V. * }
$$

Observing how these four constraints catch some fundamental realities about English syllable structure. Assume first as a word like cap [hat). This word could only be syllabified as a single syllable. Some other syllabification of this word would mean a generally unnecessary violation of PEAK/C. Another probability is to strand fragments and leave them syllabified. However that would result in Violation of PARSE. Still another plausibility is to leave segments unpronounced. But FAITH gets Violated. In this and following tableaux, unlabeled square brackets show syllable participation (Hammond, 2003.

P.44).

\begin{tabular}{|c|c|c|c|}
\hline hæt// & FAITH & PEAK/ C* & PARSE \\
\hline$[$ hæt $]$ & & & \\
\hline$[\mathrm{h}][\mathrm{t}]$ & & $!^{*}$ & \\
\hline$[\mathrm{t}[\mathrm{h} æ$ & & & $!^{*}$ \\
\hline
\end{tabular}




\begin{tabular}{|l|l|l|l|}
\hline [hæ] & $!^{*}$ & & \\
\hline
\end{tabular}

Simple Table: 6 for hat

There are still no obvious ranking connections between these constraints. The below tableau for boa [boa] demonstrates the subscript demonstrates a requirement for *ONSET/V and CoDA/V (The vowel in onset or coda position).

\begin{tabular}{|c|c|c|c|}
\hline bоə// & PARSE & ONSET/ V * & CODA/ V* \\
\hline boə]] & & & \\
\hline boㄹ] [bo] & & & $!^{*}$ \\
\hline boə & $!^{*}$ & $!^{*}$ & \\
\hline
\end{tabular}

\section{Simple Tableau:7 for boa}

Hammond, 2003:45))

Let us study the treatment of polysyllabic words. Assume first a word like puppy

[ $\left.p^{h} \wedge p i\right]$. and so far it is not clear whether the medial $p$ is could be syllabified as onset or coda.

\begin{tabular}{|r|r|r|r|}
\hline $\mathrm{p}_{\Lambda} \mathrm{pi} / /$ & FAITH & CODA/h* & PARSE \\
\hline $\mathrm{pi}]]\left[\mathrm{p}_{\Lambda}\right]$ & & & \\
\hline $\left.\mathrm{p}][\mathrm{i}] \mathrm{p}_{\Lambda}\right]$ & & & \\
\hline $\mathrm{p}[\mathrm{i}]\left[\mathrm{p}_{\Lambda}\right]$ & & & $!^{*}$ \\
\hline
\end{tabular}


CODA/h.* While , Ahab /ehæb/ is unambiguous in its syllabification because of

\begin{tabular}{|c|r|r|r|}
\hline ehæb// & FAITH & CODA/h* & PARSE \\
\hline$[\mathrm{e}][\mathrm{h} æ b]$ & & & \\
\hline$[\mathrm{eh}][$ [æ] $]$ & & !* $^{*}$ & \\
\hline$[\mathrm{e}] \mathrm{h}[æ \mathrm{~b}]$ & & & $!^{*}$ \\
\hline
\end{tabular}

\section{Table:9 unambiguous syllabification of Ahab}

Ibid

Optimality theory embraces the idea that language is a system of -1 each of ,constraints conflicting forces. These 'forces' are denoted by which makes a requirement about some aspect of grammatical output forms.

2-The Optimality theory considers that its components (GEN and EVAL) are universal. Differences in grammars reflect various rankings of the universal constraint set.

Syllable gets a crucial role in the phonological theory within the -3 framework of Optimality theory. It shows that different constraints capture crucial facts about the syllable structure, for example with the this word can only be divided as a single syllable. Some other ,'hat' word syllabification of this word would mean a generally unimportant violation of PEAK/C. thus string segments will be differently syllabified.

\section{References}

ed.). London: Teach Yourself. ${ }^{\text {th }}$ 6) Linguistics Aitchison, J. (2003).

Cambridge, MA: The MIT Press. .The Minimalist Program Chomsky, N. (1995).

.Palestine The Rise of Optimality Theory in First Century Dresher, B. E. (1996). 
January/February, p. 8.Interaction in ,2/1, GLOT International 2 Optimality Ed.),) McCarthy J. In .Grammar Generative In J. J. The Phonological Lexicon. Mester, A. (2004). \& Ito, J., (pp. 552-568). Oxford: Ed),Optimality Theory in Phonology) McCarthy Blackwell Publishing.

Cambridge: Cambridge University Press. .Optimality Theory Kager, R. (1999). Cambridge: Cambridge University Press. Optimality Theory. Kager, R. (2004).

to Guide Thematic A .(2001) J. McCarthy, Cambridge University Press. .Theory Optimality

Prosodic Morphology - Constraint "Alan Prince. \& McCarthy, John http://roa.rutgers.edu/files/> .1993."and Satisfaction Interaction July 2009]. accessed $2^{\text {nd }}$ ] .<482-1201/482-1201MCCARTHY-0-1.PDF

Optimality Theory: Constraint " Smolensky, P. (2004). \& Prince, A., in Interaction

http://roa.rutgers.edu/files/537-0 802/537-> .1993 ."Generative Grammar July 2009]. accessed $2^{\text {nd }}$ ].<0802PRINCE-0-0.PDF

New York, NY:) Pragmatics. Optimality Theory and H. Zeevat (Eds). \& R. Blutner Palgrave Macmillan.

.Learnability in Optimality Theory Tesar, B. and P. Smolenksy. (2000). MA. MIT Press Cambridge.

Remarks on the Architecture of Optimality Theoretic syntax Vogel, R. (2004). Palgrave Macmillan. London. Grammar.

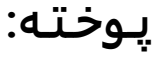

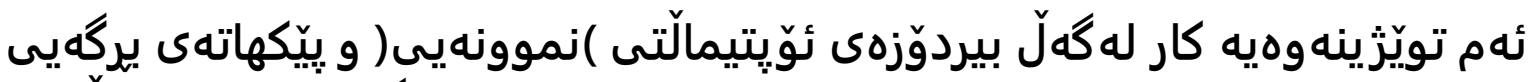

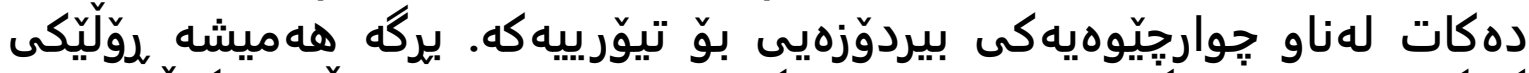

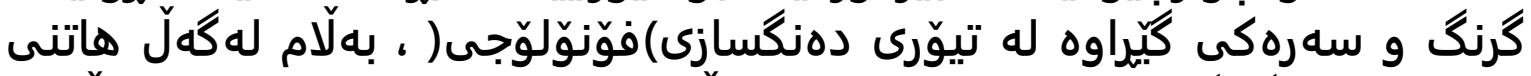

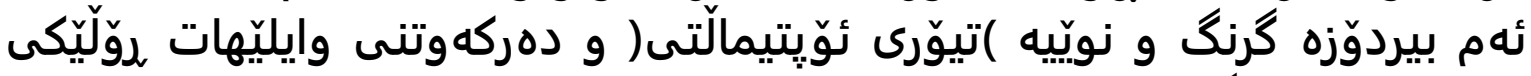

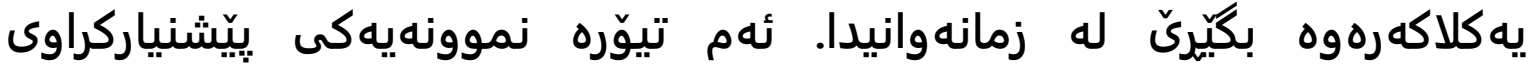

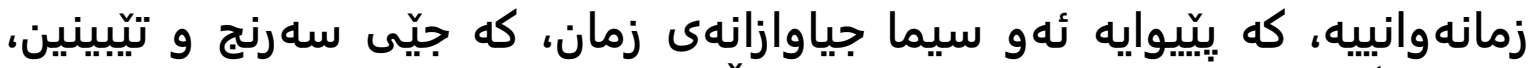

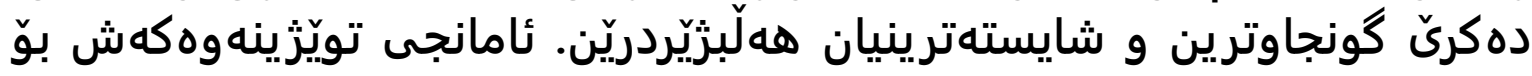




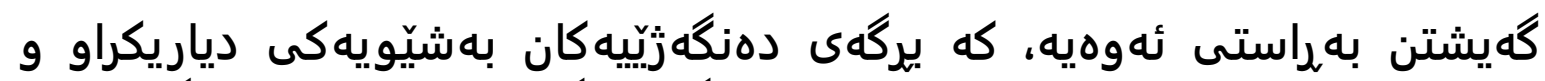

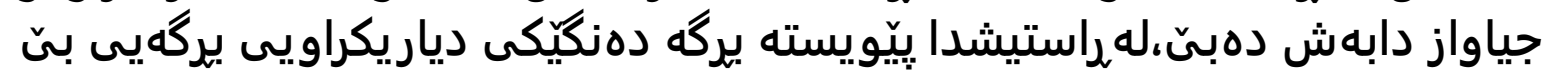

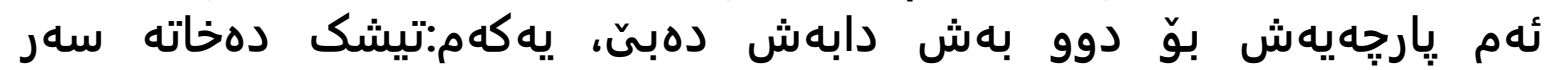

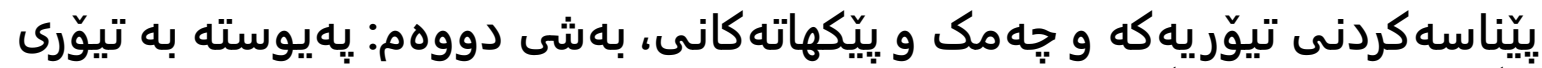

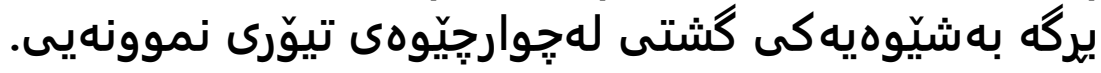

تتناول هذه الدراسة فرضية نظرية المثالية والبنية المقطعية ضمن الإطار النظري للنظرية. لعب المقطع دائم ا دو را رئيسي ا في النظرية الصوتية. ولكن في ظل ظهور نظرية التماثل الحديثة

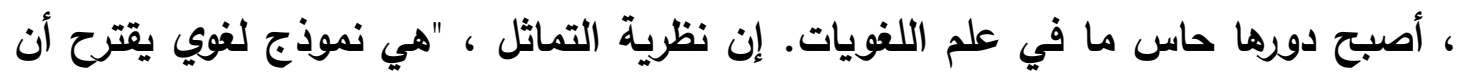

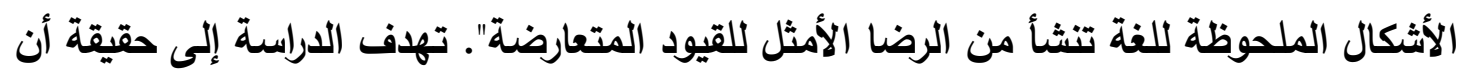

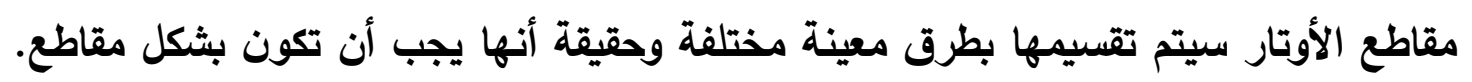
تم تقسيم هذا البحث إلى قسمين: يركز القسم الأول على تعريف النظرية ومفهومها ومكوناتها. القسم الثاني يتعلق بالنظرية العامة للمقطع في إطار نظرية المثالية. 